\title{
EFFECT OF Ag ADDITION ON THE THERMAL STABILITY AND CATALYTIC PROPERTIES OF $\mathrm{LaFeO}_{3}$ PEROVSKITE
}

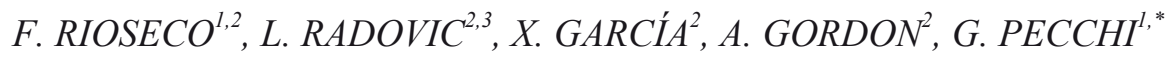 \\ ${ }^{1}$ Department of Physical Chemistry, ${ }^{2}$ Department of Chemical Engineering, University of Concepción, Concepción, Chile. ${ }^{3}$ Department of Energy and Geo- \\ Environmental Engineering, Pennsylvania State University, University Park, PA 16802, USA
}

(Received: December 2, 2009 - Accepted: January 26, 2010)

\section{SUMMARY}

The effect of low $\mathrm{Ag}$ substitution in $\mathrm{LaFeO}_{3}$ perovskite on the thermal stability and catalytic oxidation of toluene was studied. Perovskites of the type La $\mathrm{Ag}_{\mathrm{x}} \mathrm{FeO}_{3}\left(\mathrm{x}_{\mathrm{Ag}}=0.0,0.05,0.10\right)$ were prepared by the amorphous citrate method; characterized by nitrogen adsorption, XRD, FTIR, SEM-EDAX, TPR and $\mathrm{O}_{2}-\mathrm{TPD}$ techniques; and tested for the catalytic combustion of toluene in a flow reactor under excess oxygen. In comparison with the pure perovskite $\mathrm{LaFeO}_{3}$, the partially substituted $\mathrm{La}_{1-x} \mathrm{Ag}_{\mathrm{x}} \mathrm{FeO}_{3}$ present a perovskite structure with well-defined crystalline phases and greater reduction ability (attributable to the redox pair $\mathrm{Fe}^{+3} / \mathrm{Fe}^{+4}$ ). Noticeable changes in the $\alpha$ and $\beta$-oxygen contents upon silver substitution were detected. Larger content of $\alpha$-oxygen in the pure $\mathrm{LaFeO}_{3}$ perovskite is associated with greater catalytic activity. Two important effects upon $\mathrm{Ag}$ substitution in a pure $\mathrm{LaFeO}_{3}$ perovskites were observed: i) a greater reduction ability, ii) higher occurrence of oxygen vacancies due to $\beta$-oxygen desorption, which were not active in the studied reaction.

\section{INTRODUCTION}

Perovskites have been widely used as catalysts in catalytic combustion of Volatile Organic Compounds (VOCs), which is one of the most effective methods to treat these pollutants [1]. Most commercial catalysts used to destroy VOCs are based on noble metals, mainly Pt and Pd, supported in $\gamma-\mathrm{Al}_{2} \mathrm{O}_{3}[2]$. Due to the exothermal nature of these combustions, the selectivity can vary drastically [3] being highly sensitive to operating conditions.

The advantage of perovskite-type oxides with an $\mathrm{ABO}_{3}$ structure over catalysts with noble metals is that their catalytic potential to destroy VOCs may be obtained at a lower cost. There is a high number of potentially interesting perovskites for oxidation reactions, as a number of $\mathrm{A}$ and $\mathrm{B}$ cations may enter into this structure. It is well known that perovskite-like mixed oxides are able to stabilise cations with unusually high oxidation states and the anionic sub-lattice can accommodate a high concentration of vacancies. The good catalytic activity of perovskites is attributed to the oxide-reduction properties of the $\mathrm{B}$ cation, the concentration and nature of adsorbed oxygen, and the structural defects $[4,5]$. Perovskite disadvantages are their low specific surface area and the tendency to sintering. Perovskites with $\mathrm{La}$ as the A cation and $\mathrm{Co}$ or $\mathrm{Mn}$ as B cation possess high catalytic activity; moreover, the partial substitution of La by $\mathrm{Sr}$ improves the catalytic properties of these materials $[1,6]$. The catalytic activity of these perovskites are not only associated to the surface area and structural defects, but they are also significantly associated with the oxide-reduction capacity of the $\mathrm{Co}$ and $\mathrm{Mn}$ ions, as demonstrated by a considerable increase in the ion concentration ratio of $\mathrm{Mn}^{+4} / \mathrm{Mn}^{+3}$ and $\mathrm{Co}^{+3} / \mathrm{Co}^{+2}$ [1].

As structures prepared with $\mathrm{Fe}$ present less catalytic activity than those with Co [7], they are less studied in thesethis kind of application. However, the catalytic activity of $\mathrm{LaFeO} 3$ perovskite can be increased ing when by applying different preparation methods. These materials possess well-defined crystalline structures with a crystal size in the order of nm and with specific surface area of approximately $20 \mathrm{~m}^{2} / \mathrm{g}$, which is quite high value for these isese kind kind of type of oxides. Its use has allowed the complete combustion of ethyl acetate, although at elevated temperatures, in the order of $400{ }^{\circ} \mathrm{C}[8,9]$.

In the present study, $\mathrm{La}$ is partially substituted by $\mathrm{Ag}$, generating perovskites of the type $\mathrm{La}_{1-x} \mathrm{Ag}_{\mathrm{x}} \mathrm{FeO}_{3}$, which are assayed as catalysts for toluene combustion. The substitution of $\mathrm{La}^{3+}$ by $\mathrm{Ag}^{+}$, a cation with a similar radius but with a different oxidation state, deforms the crystalline structure and modifies the thermal and ionic properties of the perovskite. Thus, the main purpose of this study is to explore the structural and ionic changes in the substituted perovskite and to explain the differences between this substituted perovskite and the pure one, in the catalytic combustion of toluene, as a model reaction for VOC destruction.

\section{EXPERIMENTAL}

$\mathrm{La}_{1-x} \mathrm{AgFeO}_{3}(\mathrm{x}=0.00,0.05,0.10)$ perovskites were prepared via the amorphous citrate precursor method. Stoichiometric amounts of an aqueous solution of the nitrates of the corresponding metals were mixed with an aqueous solution of $10 \%$ of excess (in equivalent) citric acid. The resulting mixture was stirred for 15 minutes at room temperature and evaporated until forming a gel. Then, the gel was dried in an oven increasing the temperature up to $250^{\circ} \mathrm{C}$ and maintaining it overnight. The resulting powders were crushed and sieved to obtain the required particle size $(<200 \mathrm{~mm})$. Finally, the solids were calcinated at $700^{\circ} \mathrm{C}$ in air for $6 \mathrm{~h}$. The samples were labeled as $\mathrm{La}_{1-\mathrm{x}} \mathrm{Ag}_{\mathrm{x}} \mathrm{FeO}$, where $\mathrm{x}$ refers to the fraction of La substituted by Ag.

\section{Characterization}

Absorption atomic spectroscopy (AAS) was performed using a Perkin Elmer instrument model 3100 to determine the bulk composition of lanthanum, silver and iron. The specific surface areas were obtained from nitrogen adsorption isotherms at $-196^{\circ} \mathrm{C}$ in an automatic Micromeritics apparatus Model ASAP 2010, and evaluated using the BET equation. X-ray diffraction patterns were obtained on a Rigaku diffractometer using a Ni-filter and $\mathrm{CuKa}$, radiation. The crystalline phases were identified by reference to the powder diffraction data (JCPDS files). TPR and oxygen TPD experiments were performed in a TPR/ TPD 2900 Micromeritics system with a thermal conductivity detector. For the TPR experiments, the reducing gas was a mixture of $5 \% \mathrm{H}_{2} / \mathrm{Ar}\left(40 \mathrm{~cm}^{3} \mathrm{~min}^{-1}\right)$ and a heating rate of $10^{\circ} \mathrm{Cmin}^{-1}$ was employed. For the TPD experiments, the samples were exposed to oxygen for $1 \mathrm{~h}$ at $700^{\circ} \mathrm{C}$, followed by cooling to room temperature in the same atmosphere. After switching the atmosphere to a helium flow, the sample was heated at a constant rate of $10^{\circ} \mathrm{Cmin}^{-1}$ and the desorbed oxygen was monitored with a thermal conductivity detector. TPDMS experiments confirm that the evolved gas and the He flow only contain oxygen. FTIR spectra were recorded in a Nicolet Magna-IR 550 instrument equipped with a quartz sample holder with $\mathrm{KBr}$ windows. After dehydration at $210^{\circ} \mathrm{C}$, the perovskites were finely ground and mixed with $\mathrm{KBr}$ in an agate mortar, to obtain a perovskite- $\mathrm{KBr}$ ratio of $1 / 150$.

\section{Catalytic activity}

The catalytic activity for toluene combustion was assayed in a conventional flow reactor, under atmospheric pressure. In each experiment, $0.25 \mathrm{~g}$ of catalyst diluted with $1.5 \mathrm{~g}$ of $\mathrm{SiC}$ (both, 20-40 mesh; 400 a 841 microns), were loaded in a quartz reactor (i.d. $1.27 \mathrm{~cm}$ ) with quartz fiber packed at the end of the catalyst bed. Mass-flow controllers Brooks 5850E instruments were used for accurate preparation of the feed mixture and stable control of gas flow rates. Experiments carried out within a diluted bed with quarts particles of the same mesh size and with catalyst's particles of different sizes demonstrated the absence of any mass or heat transfer limitations. The mixture was bubbled with helium at $45 \mathrm{~mL} \mathrm{~min}^{-1}$ through two thermostated and pressurized saturators containing toluene at $37^{\circ} \mathrm{C}$. This stream was further mixed with helium to obtain a mixture gas of $\mathrm{C}_{7} \mathrm{H}_{8}: \mathrm{O}_{2}=0.44: 11.6$ ( $\mathrm{He}$ as balance) fed to the reactor at $250 \mathrm{~mL} \mathrm{~min}^{-1}\left(\mathrm{w} / \mathrm{F}=0.0576 \mathrm{gscm}^{-3}\right)$ measured at room temperature and reheated before entry into the reactor. The thermocouple was placed inside the reactor just at the beginning of the catalyst bed. The temperature was increased $\left(1^{\circ} \mathrm{C}\right.$ 
$\left.\min ^{-1}\right)$ up to the required value in the temperature range $\left(220-420^{\circ} \mathrm{C}\right)$, and maintained constant for $30 \mathrm{~min}$. Subsequently, it was raised with the same rate to new isothermal steps, until reaching complete conversion. Reactor effluents were analyzed by on-line gas chromatography (Hewlett Packard model HP 4890D with thermal conductivity detector). Helium was used as a carrier gas in a $30-\mathrm{m}$ capillary Supelco 25462 column.

\section{RESULTS AND DISCUSSION}

\section{$A A S$}

Table 1 presents the bulk and nominal composition for the prepared perovskites. The measured compositions for $\mathrm{Fe}$ coincided with the stoichiometric values with deviations below $10 \%$. These results indicates that no significant losses were detected for the elements considered, verifying the reproducibility of the synthesis method in terms of the bulk composition of the solids.

Table 1. Iron, lanthanum and silver bulk composition, wt $\%$ (nominal in parenthesis), for $\mathrm{La}_{1-\mathrm{x}} \mathrm{Ag}_{\mathrm{x}} \mathrm{FeO}_{3}$ perovskites.

\begin{tabular}{|c|c|c|c|}
\hline Perovskite & $\mathrm{La}(\%)$ & $\mathrm{Fe}(\%)$ & $\mathrm{Ag}(\%)$ \\
\hline $\mathrm{LaFeO}_{3}$ & $58.2(57.2)$ & $22.0(23.0)$ & $0.0(0.0)$ \\
\hline $\mathrm{La}_{0.95} \mathrm{Ag}_{0.05} \mathrm{FeO}_{3}$ & $54.9(54.7)$ & $24.4(23.1)$ & $1.4(2.3)$ \\
\hline $\mathrm{La}_{0.90} \mathrm{Ag}_{0.10} \mathrm{FeO}_{3}$ & $53.2(52.2)$ & $21.2(23.3)$ & $13.8(4.5)$ \\
\hline
\end{tabular}

Surface area

The surface areas of the studied perovskites after the calcination treatment at $700^{\circ} \mathrm{C}$ are shown in Table 1. The main effect from the preparation step is the decrease of the ionic strength by the substitution of $\mathrm{La}^{3+}$ by $\mathrm{Ag}^{1+}$ cation. This decrease allows the crystalline growth during synthesis resulting in lower $\mathrm{S}_{\mathrm{BET}}$ values. [10]. To study the effect of Ag substitution on the thermal stability, both in reducing and oxidant atmosphere, the surface area of the calcinated perovskites were evaluated after a redox cycle in $\mathrm{H}_{2}$ at $700^{\circ} \mathrm{C}$ followed by a re-oxidation at $700^{\circ} \mathrm{C}$ (values in Table 2). As observed, surface area $\left(\mathrm{S}_{\mathrm{BET}}\right)$ value decreases for the pure $\mathrm{LaFeO}_{3}$ perovskite, whereas for the $\mathrm{Ag}$-substituted perovskites that value increases, being larger for the highest Ag-substituted perovskite $\left(x_{\mathrm{Ag}}=0.10\right)$. Because $\mathrm{LaFeO}_{3}$ is an almost no-reducible perovskite, the decrease in the $\mathrm{S}_{\mathrm{BET}}$ values of this solid must be attributed to its sintering. Whereas, the increase of $\mathrm{S}_{\mathrm{BET}}$ values in the Ag-substituted perovskites be explained by the capacity of highly dispersed silver oxide (produced under oxidative conditions) to recompose the perovskite structure. Therefore, during the TPR 2 profile, the insertion of Ag into the perovskite structure increases the corresponding specific area, as shown by the $\mathrm{TPR}_{2}$ profile and discussed in the next section (TPR results).

Table 2. Specific BET values for $\mathrm{La}_{1-x} \mathrm{Ag}_{\mathrm{x}} \mathrm{FeO}_{3}$ perovskites calcinated at $700^{\circ} \mathrm{C}$ and after a redox cycle $\left(\mathrm{H}_{2}-700^{\circ} \mathrm{C}\right.$ followed by a re-oxidation at $\left.700^{\circ} \mathrm{C}\right)$.

\begin{tabular}{|c|c|c|}
\hline \multirow{2}{*}{ Perovskite } & \multicolumn{2}{|c|}{$\mathrm{S}_{\text {BET, }} \mathrm{m}^{2} \mathrm{~g}^{-1}$} \\
\hline & calcinated $700^{\circ} \mathrm{C}$ & $\mathrm{H}_{2}-700^{\circ} \mathrm{C}$ \\
\hline $\mathrm{LaFeO}_{3}$ & 19.5 & 13.6 \\
\hline $\mathrm{La}_{0.95} \mathrm{Ag}_{0.05} \mathrm{FeO}_{3}$ & 13.2 & 14.4 \\
\hline $\mathrm{La}_{0.90} \mathrm{Ag}_{0.10} \mathrm{FeO}_{3}$ & 16.7 & 18.5 \\
\hline
\end{tabular}

\section{$T P R$}

To study the thermal stability in reducing atmosphere, temperature programmed reduction and oxidation cycles were performed with the calcinated samples. A first reduction step under $\mathrm{H}_{2} / \mathrm{Ar}$ flow was carried out up to $700^{\circ} \mathrm{C}$ $\left(\mathrm{TPR}_{1}\right)$. Then, the sample was cooled in Ar flow until room temperature, and an $\mathrm{O}_{2} / \mathrm{He}$ flow was switched to the reactor. Once the base line was restored, a programmed oxidation was carried out up to $700^{\circ} \mathrm{C}$. Afterwards, the sample was cooled down again and a second reduction treatment was performed $\left(\mathrm{TPR}_{2}\right)$. Differences between the TPR's profile are indicative of changes in the perovskite structure after hydrogen treatment. Figure 1 presents the two TPR cycles for each of the studied perovskites. $\mathrm{As}^{\mathrm{La}^{3+}}$ and $\mathrm{Ag}^{+}$are almost non-reducible ions, the reduction step is attributed to the B cation [11]. As observed, no reduction of $\mathrm{LaFeO}_{3}$ takes place and almost no changes occur upon the hydrogen treatment in the TPR, profile [12], whereas changes of the material's reducibility are detected with Ag substitution. Thus, for $\mathrm{x}_{\mathrm{Ag}}=0.05$ substitution in the perovskites, a well defined reduction peak appears, while for the $\mathrm{x}_{\mathrm{Ag}}=0.10$ substitution, three reduction peaks, two of them as shoulders, appear in the TPR profile. The assignment of these reduction peaks are: i) $330^{\circ} \mathrm{C}$, highly dispersed $\mathrm{Fe}_{2} \mathrm{O}_{3}$; ii) $430^{\circ} \mathrm{C}$, redox $\mathrm{Fe}^{4+} / \mathrm{Fe}^{3}$ pair of the perovskite structure; iii) the small and broad reduction peak at $600^{\circ} \mathrm{C}$, attributed to silver segregated phases. The $\mathrm{TPR}_{2}$ for the $\mathrm{Ag}$-substituted perovskites clearly shows a more defined reduction peak, larger than the TPR of the same sample. The broader peak of the higher substituted Ag-perovskite is indicative that for this solid, a slight extent of segregated phase is present. This result is explained considering that partial reduction of $\mathrm{Fe}^{3+}$ to metallic iron occurs during TPR resulting in a defective perovskite with vacancies. Subsequently, silver that was not incorporated to the perovskite structure and the metallic iron expelled during $\mathrm{TPR}_{1}$ may enter into the $\mathrm{LaFeO}_{3}$ structure during the oxidizing step. Similar results have been reported recently for $\mathrm{Ni}$ substituted perosvkites [13]. Consequently, the $\mathrm{TPR}_{2}$ has one signal at $380^{\circ} \mathrm{C}$, corresponding to the loss of lattice oxygen to form an oxygen-deficient perovskite structure.

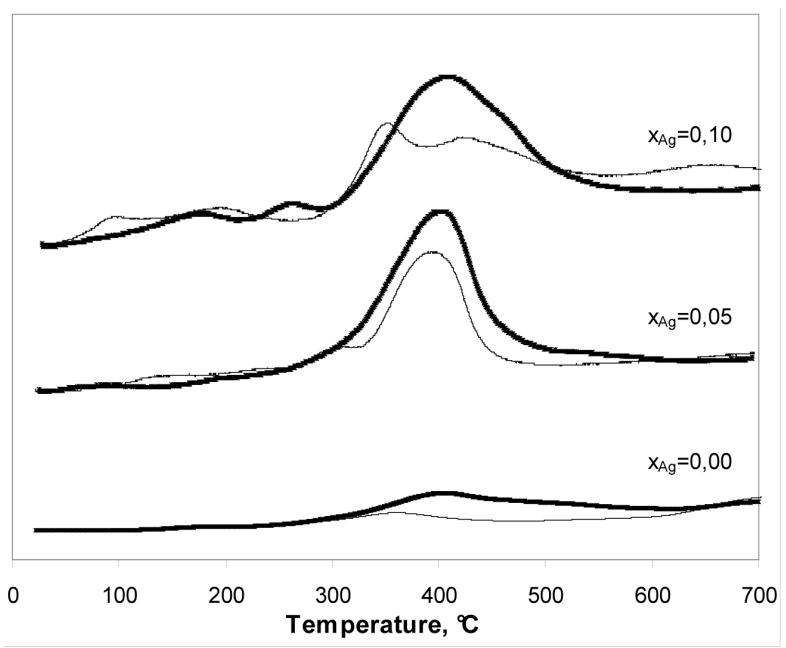

Figure 1. Redox cycles, temperature-programmed reduction $\mathrm{TPR}_{1}$ (smooth) - TPR 2 (dark) profiles of $\mathrm{La}_{1-\mathrm{x}} \mathrm{Ag}_{\mathrm{x}} \mathrm{FeO}_{3}$ perovskites.

Moreover, the higher hydrogen consumption of $\mathrm{x}_{\mathrm{Ag}}=0.10$ may be explained by the greater amount of $\mathrm{Fe}^{4+}$ ions generated to compensate the charge unbalance [14]; this is in accordance with the XRD results. It is noticeable the reversibility of the $\mathrm{TPR}_{1} / \mathrm{TPR}_{2}$ cycle for $\mathrm{x}_{\mathrm{Ag}}=0.05$, which is indicative of high thermal stability in $\mathrm{H}_{2}$ up to $700^{\circ} \mathrm{C}$, a result that agrees with $\mathrm{S}_{\mathrm{BET}}$ and XRD results to be discussed later. As expected, the non -reducible $\mathrm{LaFeO}_{3}$ perovskite does not exhibit reversibility.

$D R X$

Figure 2 shows the $\mathrm{X}$-Ray diffractograms for all the perovskites calcinated at $700^{\circ} \mathrm{C}$ and after $\mathrm{H}_{2}$ treatment at $700^{\circ} \mathrm{C}$. The crystalline structure of the perovskites was determined by comparing the diffractograms with the JCPDS 37-1493 pattern, which corresponds to $\mathrm{LaFeO}_{3}$ perovskite with an orthorhombic structure. The diffractograms adjust to the indicated pattern, showing a high degree of crystallinity, which agrees with the results reported in the literature [9]. Segregated $\mathrm{Ag}$ is observed only for the perovskite with $\mathrm{x}_{\mathrm{Ag}}=0.10$. The main diffraction lines, which adjust with the JCPDS 4-0783 pattern, correspond to cubic $\mathrm{Ag}$, at $2 \mathrm{q}$ values of $38.1,44.3,64.4$ and 77.5 . It must be pointed out that the JCPDS 37-1493 pattern .of $\mathrm{LaFeO}_{3}$ also exhibits a diffraction line for $2 q$ values of 37.94. The great similarity between the diffractograms for pure $\mathrm{LaFeO}_{3}$ and the $\mathrm{x}_{\mathrm{s}}=0.05$ substituted perovskite, before and after the $\mathrm{H}_{2}$ treatment at $700^{\circ} \mathrm{C}$, is indicative of a high thermal stability in a reducing atmosphere. For the $\mathrm{x}=0.10$ perovskite a decrease in the diffraction lines at $2 \mathrm{q}$ values of 38.1 and 44.3 , corresponding to a segregated phase of $\mathrm{Ag}$ may be observed. This behavior agrees with the previous results and may be attributed to a re-insertion of $\mathrm{Ag}$ into the perovskite structure. 


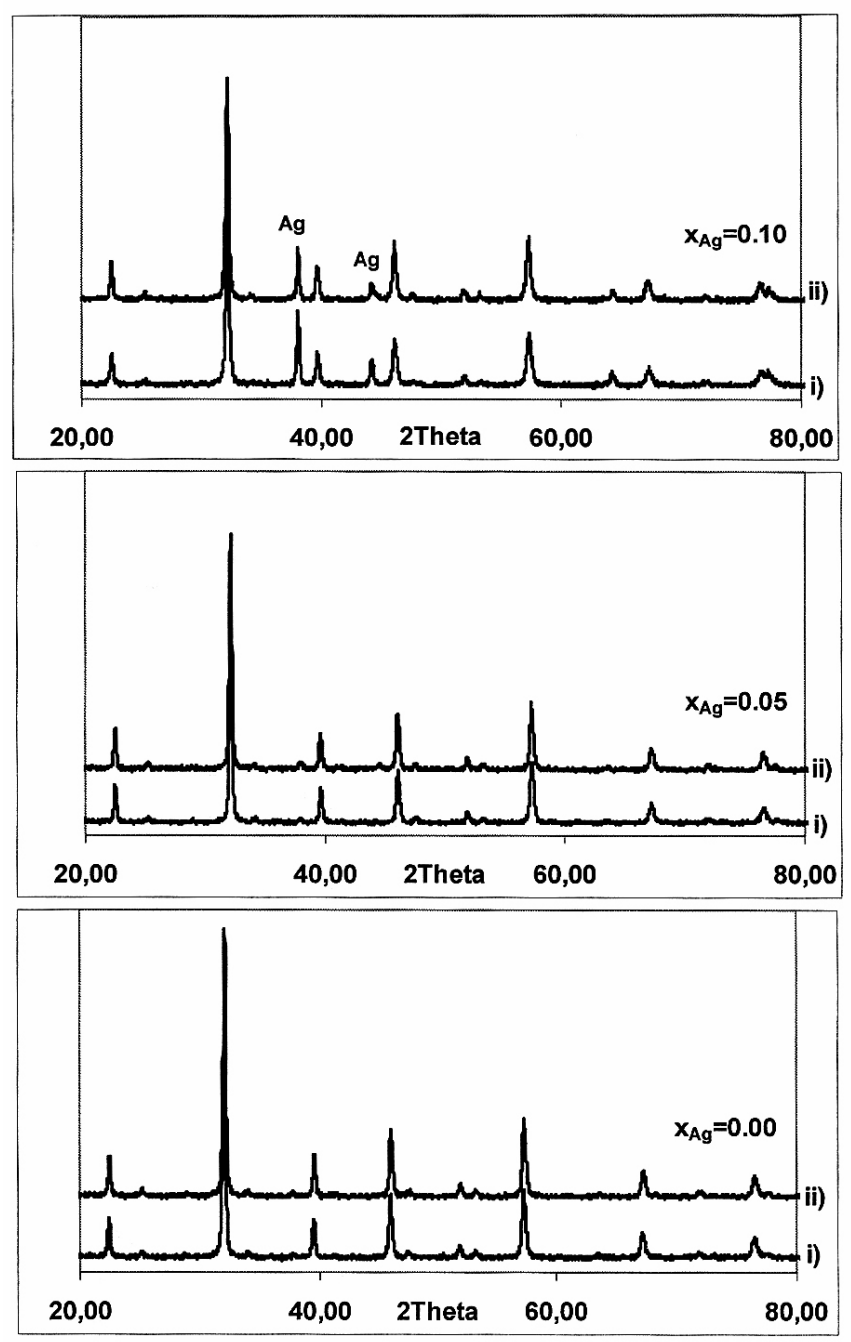

Figure 2. X-ray diffraction patterns of $\mathrm{La}_{1-\mathrm{x}} \mathrm{Ag}_{\mathrm{x}} \mathrm{FeO}_{3}$ perovskites: i) calcinated at $700^{\circ} \mathrm{C}$; ii) after $\mathrm{H}_{2}$ treatment at $700^{\circ} \mathrm{C}$.

\section{FTIR}

Figure 3 and Figure 4 show the FTIR and the far FTIR spectra of the studied perovskites. The orthorhombic structure of the perovskites is confirmed by the bands in the wavenumber regions $650-500$ and $450-250 \mathrm{~cm}^{-1}$ (Far IR) arising from the asymmetric stretching vibrations of $\mathrm{Fe}-\mathrm{O}-\mathrm{Fe}$ bonds and deformation of octahedral $\mathrm{FeO}_{6}[15]$. The similar intensity of these bands of the $\mathrm{x}_{\mathrm{Ag}}=0.05$ substituted perovskite with the pure $\mathrm{LaFeO}_{3}$ is indicative of similar crystalline degree. The bands at 1565 and $1440 \mathrm{~cm}^{-1}$ are respectively assigned to the asymmetric and symmetric O-C-O stretching vibrations of the carboxyl group [16]. A band detected near $3500 \mathrm{~cm}^{-1}$ corresponds to the lengthening of the $\mathrm{O}-\mathrm{H}$ bond of water adsorbed in the solid's pore. This is due to exposure to the moisture of environmental air. The bands that appear between 1600 and $1700 \mathrm{~cm}^{-1}$ are associated to the flexion of water's $\mathrm{O}-\mathrm{H}$ bonds and those bands between 1300 and $1500 \mathrm{~cm}^{-1}$, to a vibration mode $n_{3}$ of the carbonates. The far FT-IR spectra showed in Figure 4 display the same trend. The lower intensity of the bands is indicative of a low crystallinity.

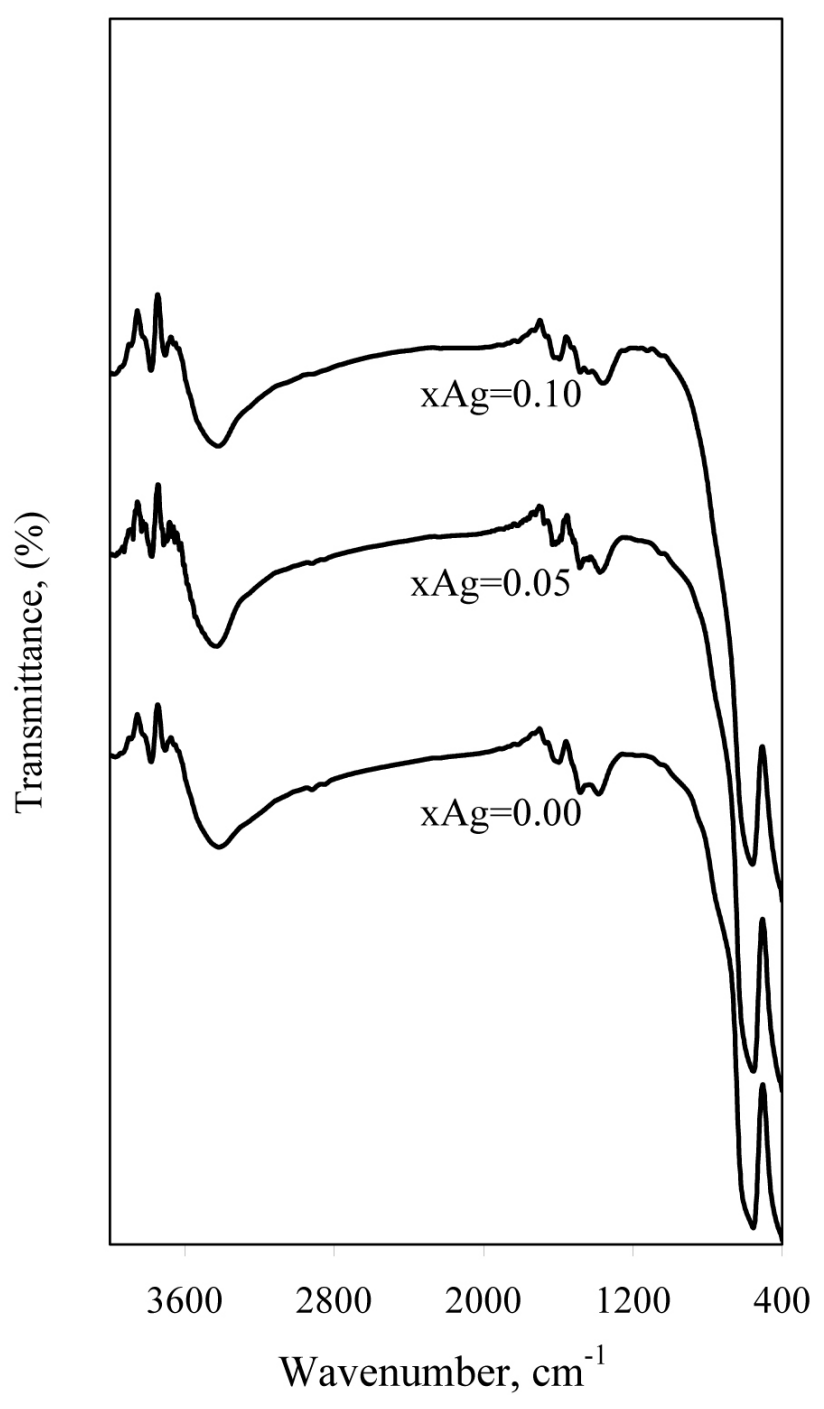

Figure 3. FTIR spectra of $\mathrm{La}_{1-x} \mathrm{Ag}_{\mathrm{x}} \mathrm{FeO}_{3}$ perovskites 


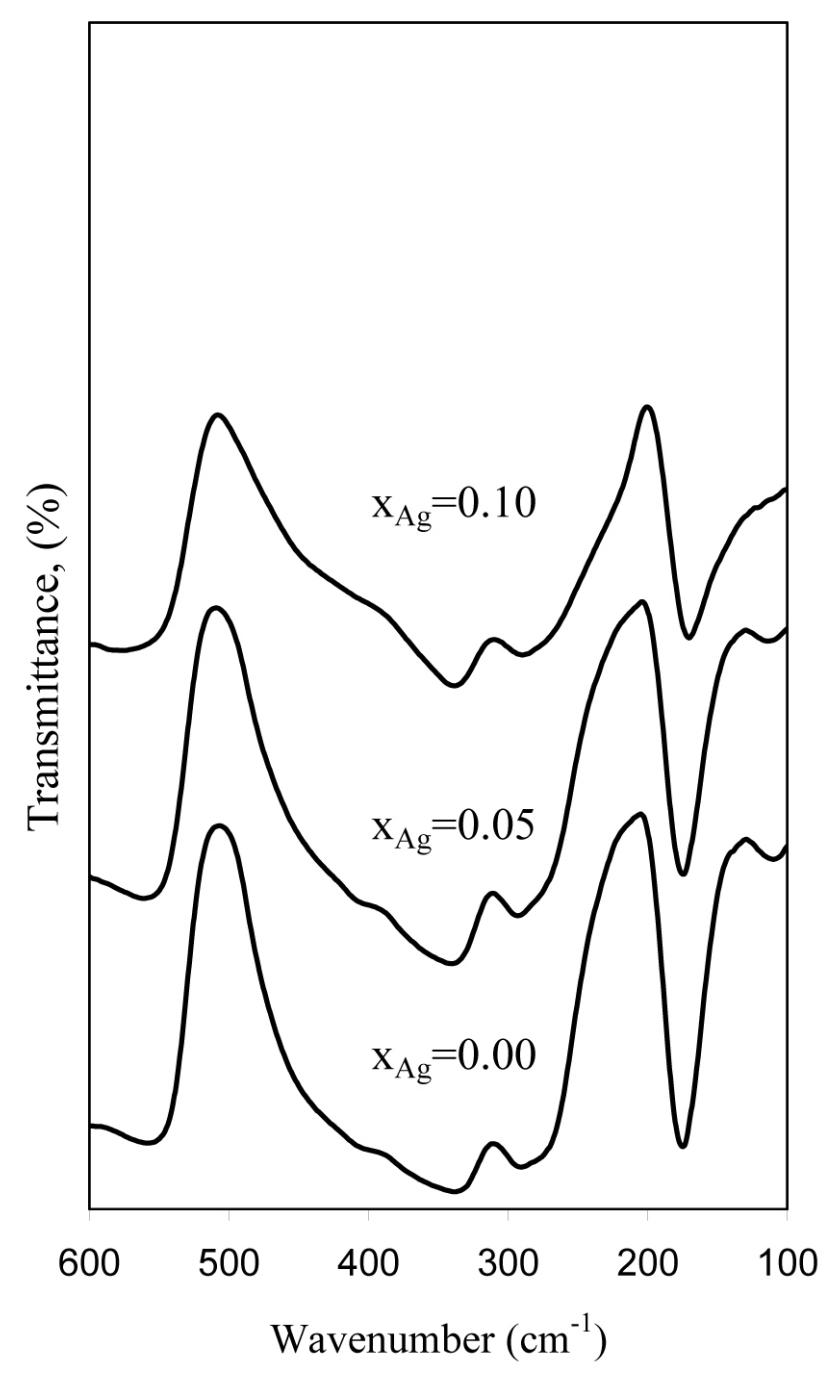

Figure 4. Far FTIR spectra of $\mathrm{La}_{1-\mathrm{x}} \mathrm{Ag}_{\mathrm{x}} \mathrm{FeO}_{3}$ perovskites.

\section{$O-D T P$}

The evolution of oxygen during temperature-programmed desorption experiments provide information dealing with the redox properties of these oxides [17]. The $\mathrm{O}_{2}$-TPD profiles are shown in Figure 5. For perovskite-type oxides three desorption peaks have been reported: i) physisorbed oxygen species, $\mathrm{O}_{2}^{-}$(ads) at temperature $<150^{\circ} \mathrm{C}$, which is almost constant for the two studied series; ii) a-oxygen species, $\mathrm{O}^{-}$at temperatures between 200 to $300^{\circ} \mathrm{C}$; iii) b-oxygen oxygen species, $\mathrm{O}^{2-}$ at temperatures higher than $350^{\circ} \mathrm{C}$ [18]. Figure 5 shows the expected trends. Physisorbed species at low temperatures and presence of $\alpha$-oxygen's as a shoulder for the pure $\mathrm{LaFeO}_{3}$ perovskites in agreement with Fino et al [19], with an increase in intensity shifting towards higher temperatures as $\mathrm{x}_{\mathrm{A}}$ values increase. The so-called $\beta$-oxygen, absent for the pure $\mathrm{LaFeO}_{3}$ show an increase in intensity upon $\mathrm{Ag}$ substitution. As this peak is associated with the lattice oxygen or with oxygen species occupying inner vacancies, the evolution of this oxygen species is a measure of the $\mathrm{La}^{3+}$ replacement by $\mathrm{Ag}^{+}$in the perovskite structure. TPD-MS experiments confirm that the evolved gas and the He flow only contain oxygen. The observed profiles agree with the previous characterization results. Pure $\mathrm{LaFeO}_{3}$ and the $\mathrm{x}_{\mathrm{Ag}}=0.05$ substituted perovskite samples exhibit similar desorption profiles. These are the two broad and small oxygen desorption peaks at 230 and $425^{\circ} \mathrm{C}$ for the $\mathrm{LaFeO}_{3}$ perovskite, and the sole peak, almost in the same temperature range, for the $\mathrm{x}_{\mathrm{Ag}}=0.05$ perovskite. The different desorption profile for the $\mathrm{x}_{\mathrm{Ag}}=0.10$ perovskite is a measure of the previously discussed changes in the $\mathrm{LaFeO}_{3}$ structure upon Ag substitution [14].

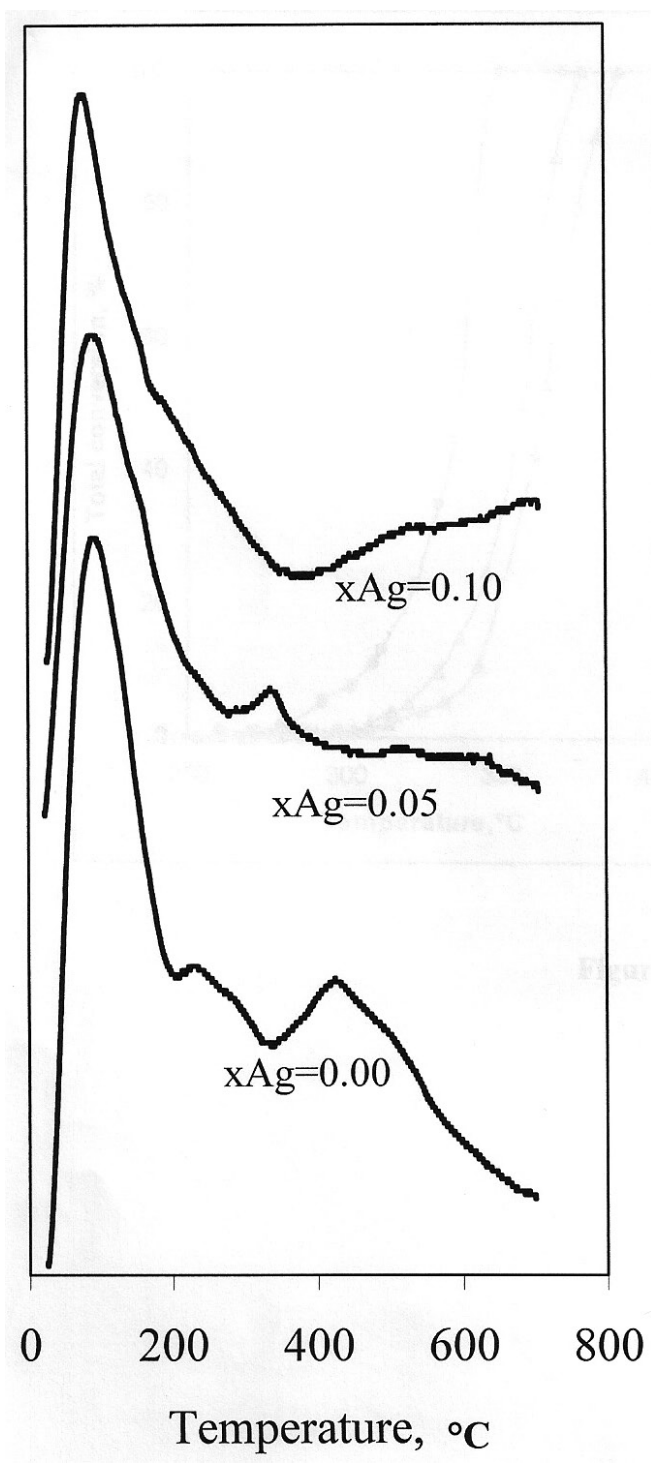

Figure 5. Oxygen profiles spectra of $\mathrm{La}_{1-x} \mathrm{Ag}_{\mathrm{x}} \mathrm{FeO}_{3}$ perovskite.

Catalytic activity

The catalytic activity of the perovskites was evaluated in toluene combustion, carried out in a flow reactor under excess oxygen. Figure 6 shows the conversion curves as a function of the reaction temperature and the Ag addition. It cab be seen Typical sigmoid curves may be observed, as the reaction starts at about $220^{\circ} \mathrm{C}$ and it reaches total conversion at temperatures lower than $400^{\circ} \mathrm{C}$. Prior to the reaction measurements, diffusion control assays were run to assure kinetic regime conditions. Table 3 comprises the catalytic results: ignition temperature, defined as the temperature required for $50 \%$ of conversion; the reaction rate referred to catalyst weight $\left(\mathrm{mmol} \mathrm{g}^{-1} \mathrm{~h}^{-1}\right)$ and catalyst surface $\left(\mathrm{mmol} \mathrm{m}^{-2} \mathrm{~h}^{-1}\right)$ at $300^{\circ} \mathrm{C}$; and the activation energies. As shown, the lowest ignition temperature, i.e. the highest catalytic activity, is obtained for the pure $\mathrm{LaFeO}_{3}$ perovskite. The reaction rates show the same trends. The maximum catalytic activity in the total combustion of toluene obtained for the pure $\mathrm{LaFeO}_{3}$ indicates neither simple dependence on the oxidation state of the metallic ion, nor dependence on the amount of adsorbed oxygen.. On the other hand, it should be considered that when the perovskite is doped with foreign ions, the ideal structure can be distorted, leading to the formation of local defects. For low contents of defects in the perovskite structure, a random distribution in the lattice of these defects and no-interaction among them has been reported [20]. On the contrary, at higher concentration, clusters and micro-domains are formed. Furthermore, the variation of structure with stoichiometry shows some effect upon the mixed oxides, changing their catalytic properties. In iron-based 
perovskites, the catalytic activity increases with a disordered distribution of oxygen vacancies, whereas an ordering of the vacancies is associated to lower activity. The highest concentration of $\alpha$-oxygen, mainly in the pure $\mathrm{LaFeO}_{3}$ perovskite, may be related with the higher catalytic activity of this solid. Therefore, the effect on the catalytic activity of the Ag-substituted perovskites should be more clearly detected for higher reaction temperatures; at high temperatures, participation of oxygen released from filled oxygen vacancies in the crystal lattice takes place [21]. Table 3 also shows the apparent activation energies $\mathrm{E}_{\mathrm{app}}$, calculated from Arrhenius plots in the range of temperatures corresponding to conversions lower than $10 \%$. Apparent activation energies and pre-exponential factors were calculated from Arrhenius plots using the reaction rate expressed as catalyst surface. The obtained results show no correlation between extent of reducibility and catalytic activity in the toluene oxidation. The pre-exponential factor is plotted in Figure 7 as a function of the apparent activation energy of the reaction. It may be observed a non-linear plot, which is indicative that a compensation effect is present [22]. Additionally, the compensatory effect is also clear from Table 3 , as $\mathrm{LaFeO}_{3}$ perovskite, to which corresponds the highest apparent activation energy, showed the highest catalytic activity. Thus, the larger increase in the pre-exponential factor is responsible that the activation energy does not vary in the same way as the catalytic activity.

Table 3. Kinetic parameters of the catalytic combustion of toluene using $\mathrm{La}_{1-\mathrm{x}} \mathrm{Ag}_{\mathrm{x}} \mathrm{FeO}_{3}$ perovskites.

\begin{tabular}{|c|c|c|c|c|}
\hline \multirow{2}{*}{ Perovskite } & \multirow{2}{*}{$\mathrm{T}_{\substack{\mathrm{ign} \\
{ }^{\circ} \mathrm{C}}}$} & \multicolumn{2}{|c|}{ Reaction rate at $300^{\circ} \mathrm{C}$} & \multirow{2}{*}{$\underset{\mathrm{kJmol}^{-1}}{\mathrm{E}_{\mathrm{a}}}$} \\
\hline & & $\underset{\mathrm{s}^{-1}}{\mathrm{mmolg}^{-1}}$ & $\underset{\mathrm{s}^{-1}}{\mathrm{mmolm}^{-2}}$ & \\
\hline $\mathrm{LaFeO}_{3}$ & 335 & 11.1 & 0.57 & 160 \\
\hline $\mathrm{La}_{0.95} \mathrm{Ag}_{0.05} \mathrm{FeO}_{3}$ & 356 & 2.3 & 0.18 & 142 \\
\hline $\mathrm{La}_{0.90} \mathrm{Ag}_{0.10} \mathrm{FeO}_{3}$ & 370 & 1.6 & 0.09 & 115 \\
\hline
\end{tabular}

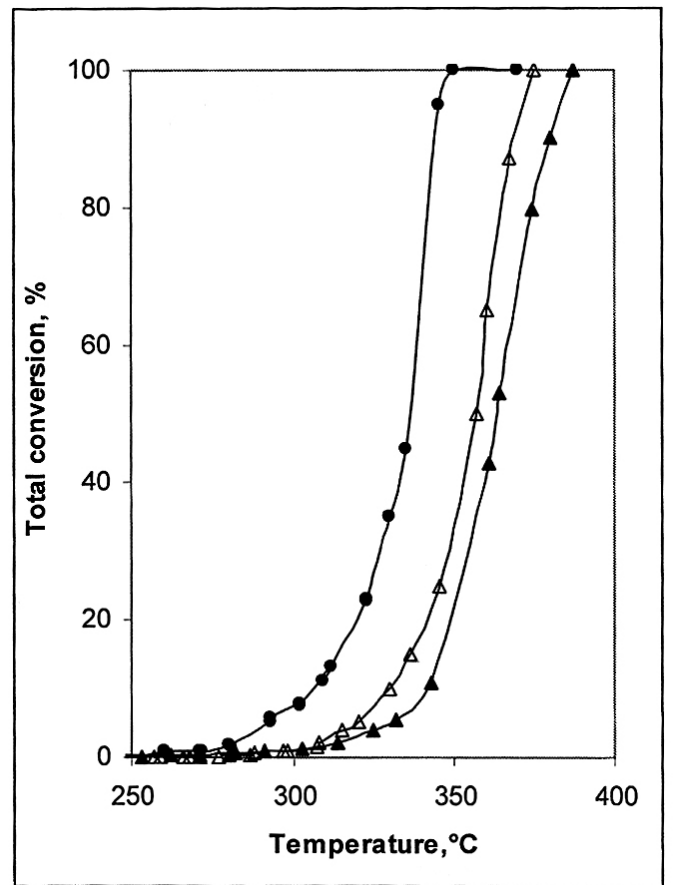

Figure 6. Stationary-state conversion over $\mathrm{La}_{1-\mathrm{x}} \mathrm{Ag}_{\mathrm{x}} \mathrm{FeO}_{3}$ perovskite for: $(\cdot)$ $\mathrm{x}_{\mathrm{Ag}}=0.00 ; \quad(\mathrm{D}) \mathrm{x}_{\mathrm{Ag}}=0.05 ; \quad(\boldsymbol{\Delta}) \mathrm{x}_{\mathrm{Ag}}=0.10$

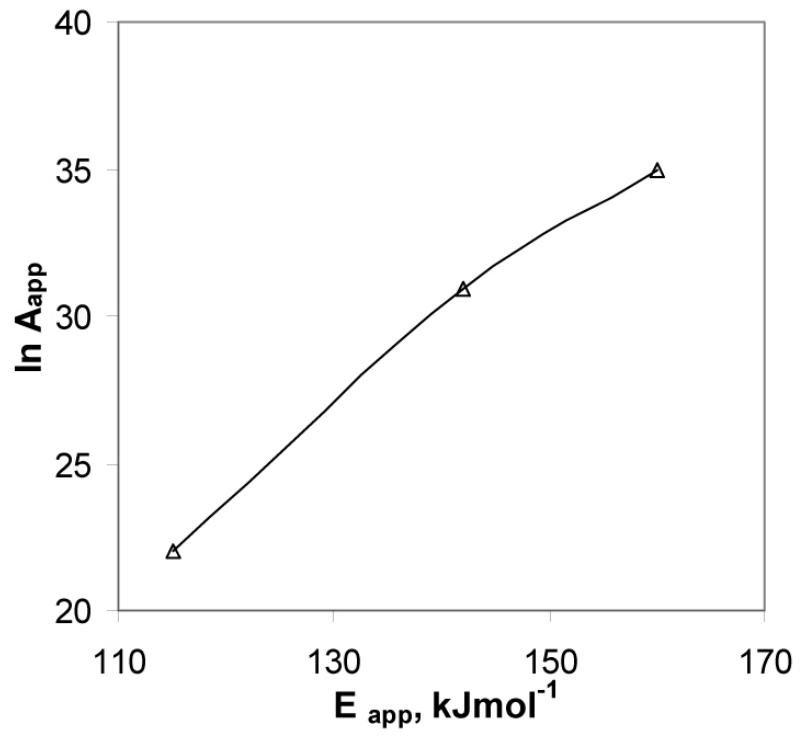

Figure 7. $\mathrm{Ln} \mathrm{A}$ as a function of $\mathrm{Ea}$ for $\mathrm{La}_{1-\mathrm{x}} \mathrm{Ag}_{\mathrm{x}} \mathrm{FeO}_{3}$ perovskite.

\section{CONCLUSIONS}

The effect of substituting a monovalent $\mathrm{Ag}^{1+}$ ion for a trivalent $\mathrm{La}^{3+}$ ion produces a non-stoichiometric perovskite with electronic properties clearly different from the starting material. No increase in the catalytic activity for the complete combustion of toluene upon Ag substitution was observed. This result is attributed to the formation of vacancies associated to the presence of $\beta$-oxygen in $\mathrm{LaFeO}_{3}$ perovskite upon $\mathrm{Ag}$ substitution. As $\beta$-oxygen are associated to the lattice of the network, to participate as active catalytic sites they must migrate to the surface through anionic vacancies. Therefore, it was concluded that $\beta$-oxygen might participate in reactions at higher temperatures. The greater catalytic activity shown by the pure perovskite of $\mathrm{LaFeO}_{3}$ in the complete combustion of toluene may be attributed to the highest specific area, higher amount of a-oxygens and remarkable stability under redox cycles.

\section{ACKNOWLEDGEMENTS}

The authors acknowledge financing support from Fondecyt-Chile, through Grant 10900018

\section{REFERENCES}

[1] J. Niu, J. Deng, W. Liu, L. Zhang, G. Wang, H. Dai,H. He, X. Zi, Catal. Today, 126 (2007) 420

[2] P. Papaefthimiou, T. Ioannides, X. Verykios, Appl. Catal.B-Environ, 13 (1997) 175

[3] J. Sawyer, M. Abraham, Ind.Eng. Chem. Res.,33 (1994), 2084

[4] Z. Yu, L. Gao, S. Yuan, Y. Wu, J. Chem. Soc. Faraday Trans., 88 (1992) 3245

[5] C. N. R. Rao and J. Gopalakrishnan, New Directions in Solid State Chemistry, Cambridge University Press, Cambridge, 1997, p.53.

[6] V. Blasin-Aubé, J. Belkouch,L. Monceaux, Appl. Catal.B- Environ, 43 (2003) 175

[7] J. Kuhn, U. Ozkan, J Catal. (2007), doi:10.1016/j.jcat.2007.10.005.

[8] V. Szabo, M. Bassir, A. Van Neste, S. Kaliaguine, Appl. Catal.B-Environ, $37(2002) 175$

[9] R. Spinicci, A. Tofanari, A. Delmastro, D. Mazza, S. Ronchetti, Mater. Chem. Phys. 76 (2002) 20

[10] H. Chen, A. Sayari, A. Adnot, F. Larachi, Appl. Catal B, 32 (2001) 195

[11] N. Merino, B. Barbero, P. Ruiz, L. Cadús, J. Catal. 240 (2006) 245

[12] J.M. Giraudon, A. Elhachimi, F. Wyrwalski, S. Siffert, A. Aboukais, J.F. Lemonier, G. Leclercq, Appl. Catal B. 75 (2007) 157

[13] M.E. Rivas, C.E. Horri, J.L.G. Fierro, M. R. Goldwasser, A. GribovalConstant, J Power Sources, 184 (2008) 265

[14] Z. Zhao, X. Yang, Y. Wu, Appl. Catal. B-Environ, 8 (1996) 281 
[15] P. Ciambelli, S. Cimino, L. Lisi, M. Faticanti, G. Minelli, I. Pettiti, P. Porta, Appl. Catal. B: Environ. 33 (2001) 193

[16] G Pecchi, P. Reyes. R.Zamora. C. Campos, L.E. Cadús, B.P. Barbero. Catal Today, 133 (2008) 420

[17] M. Imamura, N. Matsubayashi, H. Shimada, J. Phys. Chem. B, 104 (2000) 7348
[18] N. Merino, B. Barbero, P. Grange, L. Cadús, J. Catal., 231 (2005) 232

[19] D. Fino, N. Russo, G. Saracco, V. Specchia, J. Catal, 217 (2003) 367.

[20] Wu, Y. Yu, T. Dou, B. Wang, C. Xie, X. Yu, Z. Fan, S. Fan, Z. Wang, L. J. Catal. 120 (1989) 88

[21] A. Machoki, T. Ionnides, B. Stasinska, W. Gac, G. Avgouropoulos, D. Delimaris, W. Grzegorczyk, S. Pasieczna, J. Catal 227(2004) 282

[22] D. Delimaris, T. Ioannides, Appl. Catal. B, 84 (2008) 303. 